\title{
Coarctation of aorta in adults: a narrative review of surgical and endovascular management
}

\author{
Bashi V. Velayudhan, A. Mohammed Idhrees \\ Institute of Cardiac and Aortic Disorders (ICAD), SRM Institutes for Medical Science (SIMS Hospital), Vadapalani, Chennai, India \\ Contributions: (I) Conception and design: Both authors; (II) Administrative support: Both authors; (III) Provision of study materials or patients: \\ Both authors; (IV) Collection and assembly of data: Both authors; (V) Data analysis and interpretation: Both authors; (VI) Manuscript writing: Both \\ authors; (VII) Final approval of manuscript: Both authors. \\ Correspondence to: Dr. A. Mohammed Idhrees, MCh, FAIS. Cardiovascular and Thoracic Surgeon, Institute for Cardiac and Aortic Disorders, SRM \\ Institute of Medical Sciences (SIMS Hospitals), Chennai 600 026, India. Email: a.m.idhrees@gmail.com.
}

\begin{abstract}
Coarctation of the aorta (CoA) accounts for 5-8\% of all congenital heart diseases. Without correction, the mean life expectancy of patients with CoA is 35 years and $90 \%$ of those patients die before reaching the age of 50 years. The various treatment options include endovascular, surgery and hybrid procedures. The endovascular treatment includes simple balloon dilatation, stent placement, and stentgraft placement. Though endovascular approaches are gaining popularity, not all CoA are suitable for the procedure. It depends on the anatomy of the lesion, associated pathology and clinical condition of the patient. The surgical techniques include resection and end-to-end anastomosis, subclavian flap repair, prosthetic patch repair and prosthetic interposition tube graft. These open surgeries can be performed with or without the aid of cardiopulmonary bypass (CPB) depending on the anatomy and collateral circulation. When using $\mathrm{CPB}$ for the surgery it can be performed either in normothermic or hypothermic circulatory arrest (HCA) or selective right lung ventilation with partial CPB. Meticulous care is taken during surgery, as we can encounter a lot of collaterals, which when damaged can cause profuse bleeding. Further adult CoAs are complicated by intracardiac abnormalities. These patients are managed either in a single or two stages which included extraanatomic bypass or hybrid procedures. A multidisciplinary team (consisting of cardiothoracic surgeon, interventional radiologist, cardiologist, and anaesthetist) are required to manage the unique and complex problems that affect these patients. The current management options are reviewed.
\end{abstract}

Keywords: Aorta; aortic surgery; coarctation of aorta (CoA); adult coarctation; collateral circulation

Received: 01 January 2020; Accepted: 27 July 2020; Published: 20 April 2021.

doi: 10.21037/jovs-19-196

View this article at: http://dx.doi.org/10.21037/jovs-19-196

\section{Introduction}

Coarctation of aorta (CoA) is a congenital cardiac defect which may present in adulthood. These lesions can be an isolated pathology or associated with other cardiovascular lesions like bicuspid aortic valve aortic arch hypoplasia, subaortic stenosis, etc. In $10 \%$ of the patients it may be associated with cerebral aneurysm. CoA is defined as a localised narrowing of the aortic lumen by a ridge, composed of medial wall thickening and infolding of aortic wall tissue. The key factor in this review is to enlighten the difference in management between the adult and paediatric cohort. The intensity of collaterals, elasticity of the aorta, pliability of the chest wall, overall growth potential of the children and associated pathology makes the management of these two cohorts different. This review aims at the management of adult $\mathrm{CoA}$ with clinical scenarios and treatment option. We present the following article in accordance with the Narrative Review reporting checklist (available at https://jovs.amegroups.com/article/ view/10.21037/jovs-19-196/rc). 

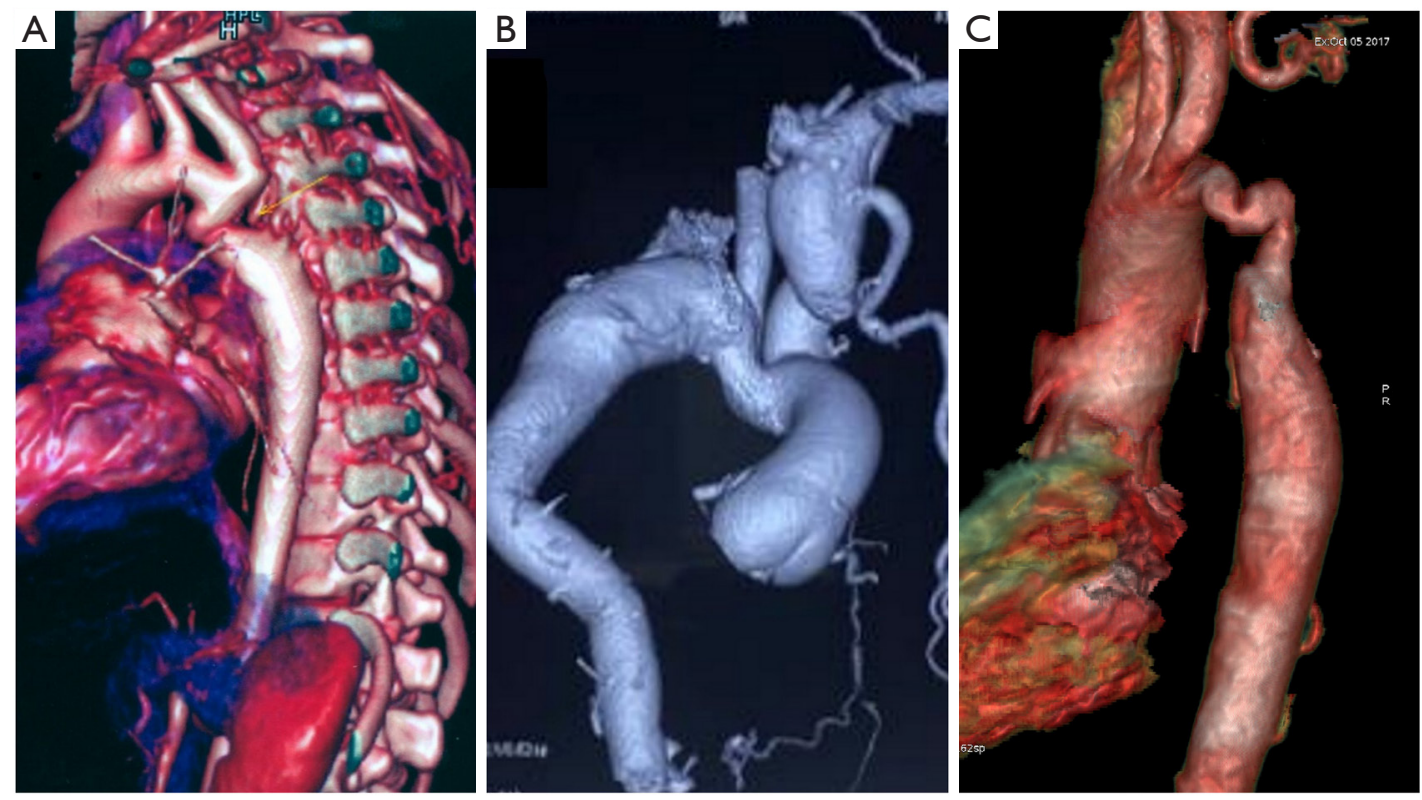

Figure 1 Classification of the coarctation of aorta. (A) CoA with discrete narrowing; (B) isthmic hypoplasia; (C) tubular or diffuse stenosis (CoA segment is more than $>10 \mathrm{~mm}$ ).

\section{Incidence}

Coarctation of the aorta (CoA) accounts for $5-8 \%$ of all congenital heart diseases, and the prevalence of the isolated form is approximately 3 per 10,000 live births (1). Without correction, the mean life expectancy of patients with aortic coarctation is 35 years and $90 \%$ of those patients die before reaching the age of 50 years.

\section{Methods}

On the basis of a large shared experience in the management of $\mathrm{CoA}$, the authors were solicited to contribute a review on the management of CoA in adult patients. One of the authors Dr. BVV presented the work at the "Tenth postgraduate course - surgery of the thoracic aorta", Bologna, Italy in November 2019. In order to prepare for the research relating to the topic, the following terminology were used in search in PubMed, Google scholar, and Embase- "Coarctation of the aorta", "Adult Coarctation", "surgery in Coarctation of the aorta", "Management of Coarctation of the aorta".

\section{Anatomy}

The most common site for CoA is adjacent to the ductus arteriosus. Classification of the CoA can be (I) discrete narrowing; (II) isthmic hypoplasia (the narrowing is $<75 \%$ of the transverse aortic diameter); (III) tubular or diffuse stenosis (the narrowing is $>10 \mathrm{~mm}$ ) (Figure 1). The anatomy of the lesion with the associated intracardiac lesion dictates the type of operation for the patient.

\section{Treatment options}

\section{Endovascular repair}

Endovascular repair is usually performed under general anaesthesia or heavy sedation because coarctation dilatation can be extremely painful. Three options are available (2).

(I) Simple dilatation: borderline stenosis and CoA which are anatomically unsuitable for stent placement. But this procedure has a high rate of recurrence.

(II) Stent placement: significant stenosis in close proximity to supraortic arch vessels.

(III) Stent-graft placement: tight stenosis, older patients, and post-stenotic dilatation.

Angioplasty increases the lumen by stretching the intimal layer of coarcted segment. Caution is required for elderly patients, especially if the aorta is calcified, because degenerative disease may further weaken the 

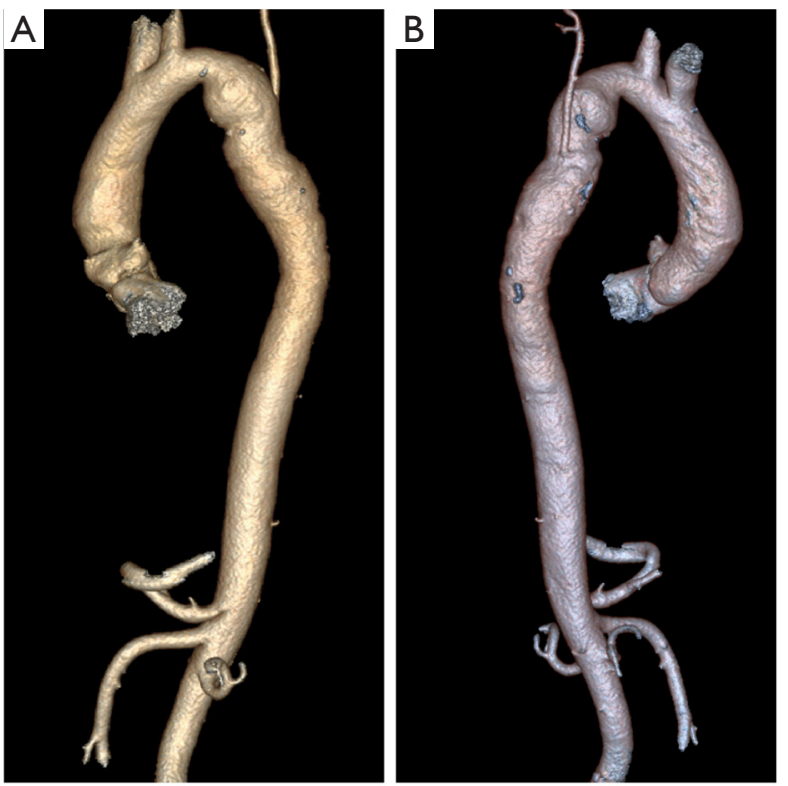

Figure 2 Subclavian flap repair in CoA. Follow up CT aortogram of 52-year-old male who underwent subclavian flap repair with close mitral valvotomy at the age of 17 years (A); the origin of the left vertebral artery can be well appreciated (B)

arterial wall (3). Under distension can cause residual stenosis while overdistension can lead to aortic dissection, rupture or aneurysmal formation (4).

\section{Open surgery}

\section{Resection and end-to-end anastomosis}

This approach was introduced by Crafoord and Nylin (5) in 1945. It is seldom used for adults as there is insufficient normal tissue after resection of the CoA. Further the aorta is less elastic as compared to children and abundant collateral makes the mobilisation of the aorta more difficult.

\section{Subclavian flap repair}

The left subclavian artery (LSA) is ligated. A flap is generated by extending the incision from the LSA to the coarcted segment of the aorta. The coarctation is opened and LSA is used as a patch to widen. The patch has significant growth potential. The re-CoA rate when performed in older children is up to $3 \%$ (6). It is not recommended for the adult as it may cause claudication of the affected arm in the long term.

Case \#1: in 1984 at the age of 17 years a patient underwent subclavian flap repair with close mitral valvotomy. $\mathrm{He}$ is at

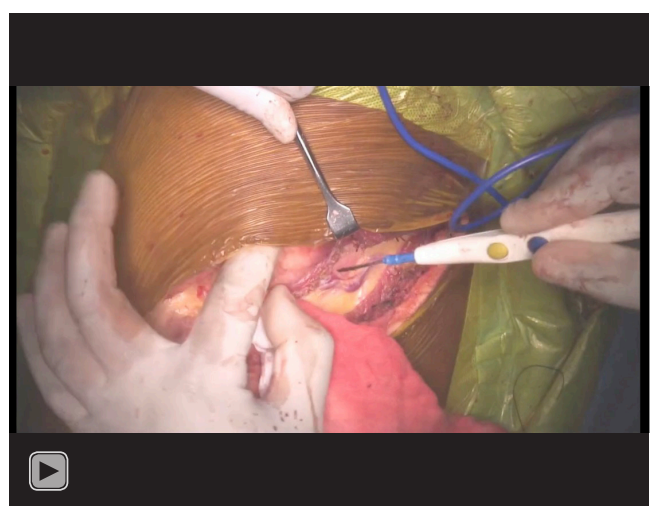

Video 1 Video showing how meticulously the collaterals on the chest wall has to handle during thoracotomy.

present on follow up and CT aortogram taken in 2019 shows no residual gradient or pseudoaneurysm (Figure 2).

\section{Prosthetic patch repair}

To reduce the incidence of re-CoA, variety of material has been used to augment the coarcted segment. The aorta is clamped on either side of the CoA, opened longitudinally, and augmented using a prosthetic patch (Dacron, PTFE). This technique initially resulted in less frequent re-CoA compared to the end-to-end repair, but there was a high incidence of aneurysm formation (20-40\%) (7). Hence it is not used in present day practise.

\section{Prosthetic interposition tube grafts}

This is the preferred technique for adult patients wherein a vascular graft is sewn onto the aorta bypassing the coarcted segment either as end-to-end or side-to-side depending upon the anatomy. It is not recommended for children due to the concern of outgrowth of the aorta.

\section{Incision}

CoA repair is usually performed through left thoracotomy. When concomitant cardiac surgery procedures are needed, few surgeons have performed the surgery through midline sternotomy as well. The best exposure of the lesion during left thoracotomy is through the $3 \mathrm{rd}$ or 4th intercostal space. The adult patients tend to have extensive collaterals along the ribs and within the muscles. These collaterals tend to be large, fragile and thin walled. Meticulous care needs to be taken to handle them. Once they are identified they are transfixed and ligated. If damaged, they tend to retract inside the muscle instantaneously causing profuse bleeding (Video 1). 


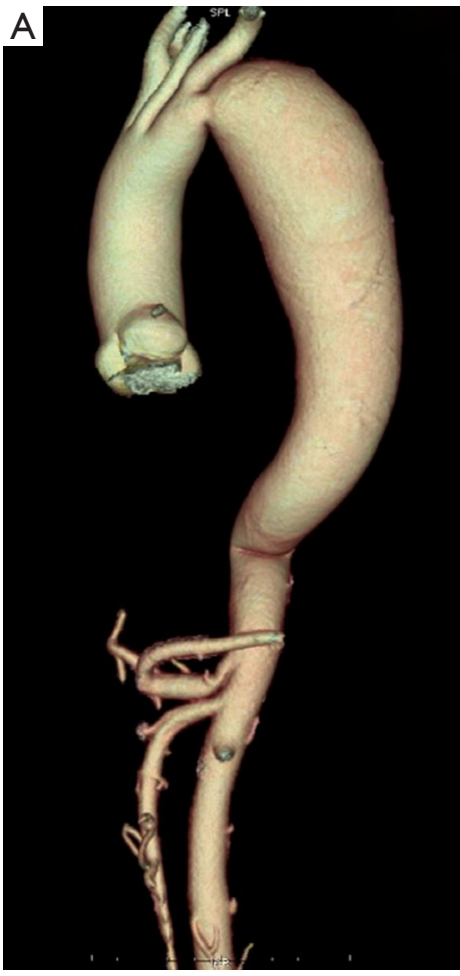

B
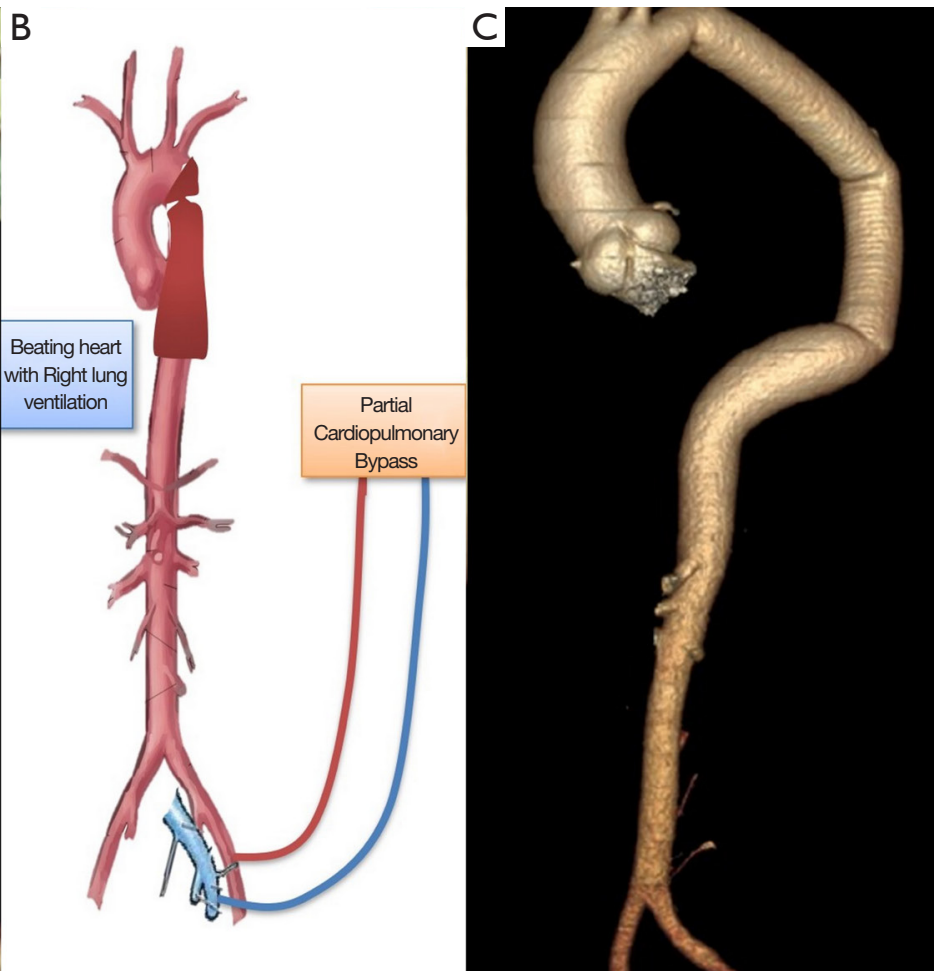

Figure $3 \mathrm{CoA}$ with descending thoracic aorta aneurysm in a 36-year-old male (case \#2). Preoperative CT aortogram showing CoA with descending thoracic aorta aneurysm of $5 \mathrm{~cm} \times 15 \mathrm{~cm}(\mathrm{~A})$. A cartoon representing the strategy for surgery using selective right lung ventilation with partial $\mathrm{CPB}$ (B). Postoperative CT aortogram of the patient (C). CPB, cardiopulmonary bypass.

When performing surgery through midline, collaterals can be avoided as it involves no muscle cutting. In patients requiring coronary artery bypass grafting and if left internal mammary artery (LIMA) is to be used, extreme care is required when harvesting the same. LIMA and its intercoastal branches are much larger than normal requiring meticulous handling.

\section{Cardiopulmonary bypass (CPB)}

Long segment CoA, CoA associated with aneurysm of the descending aorta, hypoplastic arch or other associated anomalies may warrant $\mathrm{CPB}$ or a left heart bypass. When a trial clamp is attempted and there is a drop in femoral arterial pressure, it needs either one of the bypasses as these patients may not have sufficient collaterals to sustain distal perfusion. Further it may also imply that the flow through the coarcted segment was enough to perfused the distal aorta. If carefully analysed preoperatively these patients may benefit from angioplasty (8). The strategies for CPB include:

(I) Normothermic CPB: the surgery is performed under normothermia. When the surgery is performed from median sternotomy, two arterial cannulations are used-axillary and femoral artery.

(II) Hypothermic circulatory arrest (HCA): at certain times the anastomosis has to be performed on the aortic arch which necessitates an open arch anastomosis. Under such conditions, HCA with selective cerebral perfusion can be used (9).

(III) Selective right lung ventilation with partial CPB: $\mathrm{CPB}$ is established with femoral vessels. Under normothermia, selective ventilation of the right lung and beating heart the brain and myocardium are perfused. The mean arterial pressure in the radial artery should be maintained at 65 to $70 \mathrm{mmHg}$. When the aorta is cross clamped the distal aorta is perfused by the CPB.

Case \#2: a 36-year-old male presented with dyspnoea on exertion and back pain for 2 month. He was diagnosed to have CoA with descending thoracic aorta aneurysm (5 $\mathrm{cm} \times 15 \mathrm{~cm})$. He underwent single stage correction of the CoA and the aneurysm using the above technique (Figure 3, Video 2). 


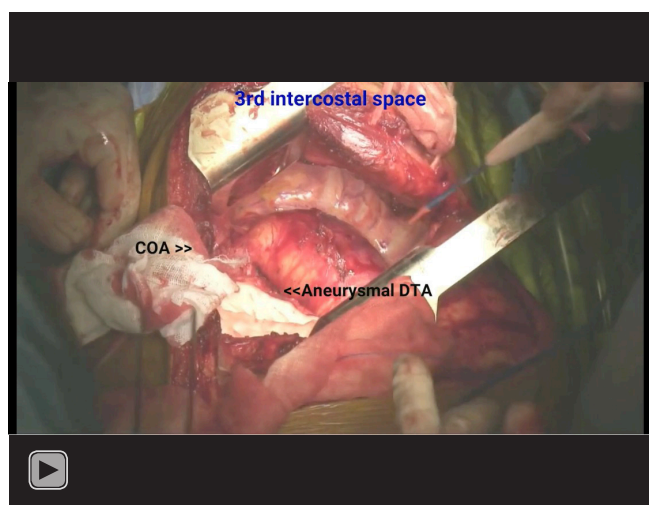

Video 2 Operative video of case \#2.

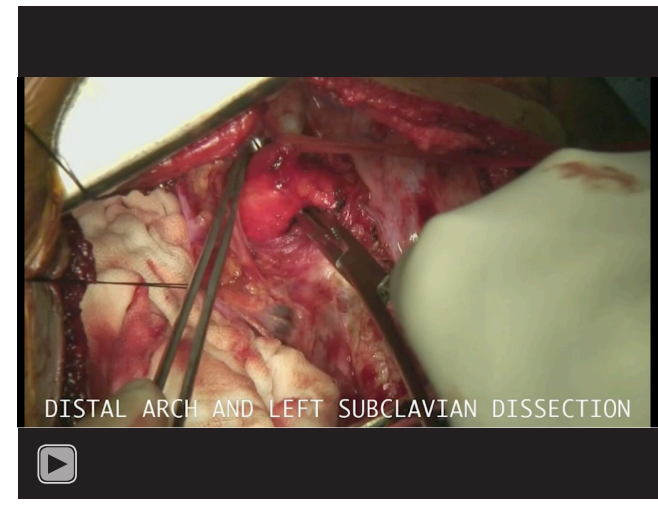

Video 3 Operative video of case \#3.
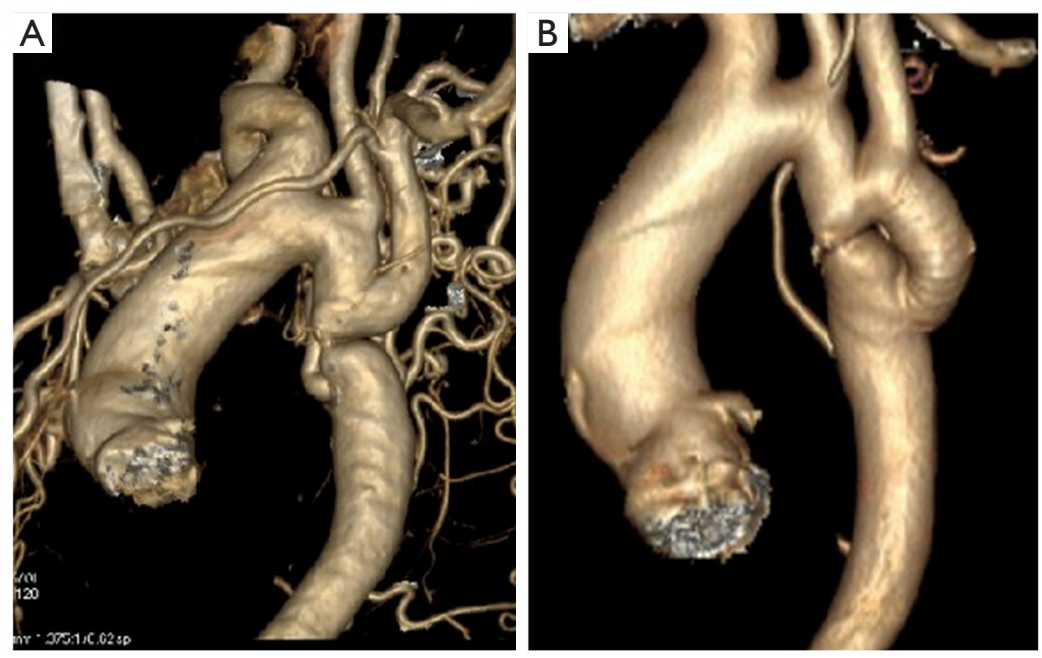

Figure 4 A 28-year-old female with discrete CoA and extensive collaterals (case \#3) Preoperative CT aortogram showing the discrete segment of CoA. Note the extensive collaterals in this patient (A). Postoperative CT aortogram with a prosthetic interposition graft (B).

\section{Isolated CoA—off-pump resection and anastomosis}

Isolated CoA is best approached through left thoracotomy. The type of surgery performed is dictated by the anatomy and the extent of the lesion.

Upper and lower body arterial pressure are monitored. Monitoring of femoral arterial pressure ensures the distal perfusion beyond the CoA. After dissection of the aorta, a trial of cross clamp is attempted above and below the coarcted segment. Absence of fall in femoral arterial pressure, indicated a collateral flow maintaining the distal perfusion. In such cases, the surgery can be performed without the need of CPB.

Case \#3: a 28-year female presented with dyspnoea on exertion for 3 months duration. She is a known hypertensive on two anti-hypertensive drugs. She was diagnosed to have a discrete CoA with extensive collaterals. She underwent interposition prosthetic graft without the aid of CPB (Figure 4 and Video 3).

\section{CoA with intracardiac abnormalities}

Patients with complex CoA concomitant with intracardiac abnormality pose a difficult surgical problem. Various surgical options have been proposed and practised. Yet up until now, there has been no universal consensus on an optimal way to manage complex CoA. The intracardiac abnormalities are corrected simultaneously in a single stage or in two different stages. A catheter based intervention for CoA followed by sternotomy for intracardiac abnormality 
Table 1 Merits and demerits of extraanatomical bypasses (I) ascending aorta to descending thoracic aorta (II) ascending aorta to abdominal aorta

\begin{tabular}{ll}
\hline Merits & Demerits \\
\hline Ascending-to-descending aortic bypass grafting & Exposure of DTA technically more difficult \\
Single incision-median sternotomy & Difficult to control bleeding if any \\
Avoid handling of peritoneal organ and possibly prevent future adhesions & \\
Lesser chance of infection when bowel not handled & \\
Ascending-to-abdominal aortic graft bypass & Two separate incision \\
Exposure of Abdominal aorta is simple and easy & Increased chance of infection \\
Can be performed without the aid of CPB & Longer graft which may cause kinking \\
\hline
\end{tabular}

DTA, descending thoracic aorta; CPB, cardiopulmonary bypass.

is an alternative. Besides that, various extra anatomic bypass has also been practised by few groups of surgeons.

Single stage or two stage

Conventionally two stage repair mandating two different surgery was practised. CoA repair was performed through thoracotomy and later the intracardiac abnormality was corrected through a sternotomy. Though it offers simple surgery for both the lesion, there are possible chances for hemodynamic instability or malperfusion. Further it adds to the hospital stay and increase the financial burden of the patient.

One stage repair simplifies this but at the cost of increased CPB time. It is technically more difficult for the surgeon. In single stage surgery, sternotomy is performed and CPB is established (10). During cooling of the patient the intracardiac correction is done. When the desired temperature is approached, the heart is retracted superiorly, and the posterior pericardium is incised exposing the descending thoracic aorta. The vascular graft is anastomosed to the descending thoracic aorta. The proximal anastomosis is performed to the aortic arch.

\section{Extra anatomic bypass}

CoA is repaired by performing an anastomosis from the ascending aorta to the descending thoracic aorta or the abdominal aorta. This technique can be used for interrupted aortic arch and more frequently with concomitant intracardiac abnormalities. In Re-CoA, adhesions from previous surgery may make a left thoracotomy approach difficult and dangerous. In such cases extra-anatomical repair can facilitate an alternative option.
The anastomosis can be performed in the descending thoracic aorta or abdominal aorta, but each technique has its own merits and demerits which is enlisted in the Table 1 (11).

Case \#4 (12): at the age of 11 years [1984] a patient underwent repair for CoA by interposition prosthetic graft. He was reoperated 3 years later [1987] for Re-CoA with and arch to descending aorta bypass graft. At the age of 18 years [1991] he presented with haemoptysis. Angiogram showed aneurysm at the proximal anastomotic site, which was eroding into the left lung for which he underwent an extra-anatomical graft from the ascending aorta to the abdominal aorta with a prosthetic graft. The aneurysmal thoracic aorta was excised through a left thoracotomy on femorofemoral bypass. At the age of 32 years [2004] he was diagnosed to have dilated ascending aorta (more than $8 \mathrm{~cm}$ ) with severe aortic regurgitation. He underwent Bentalls procedure for the same (Figure 5 and Video 4).

\section{Hybrid approacb}

This approach used a percutaneous transaortic intervention followed by median sternotomy for intracardiac abnormalities. This leads to reduced trauma, shortened hospital stay and speedy recovery. Few authors have approached the coarcted segment transluminally from the ascending aorta after sternotomy and later performed the intracardiac repair (13).

Case \#5: a 37-year male presented with dyspnoea on exertion for 3 months. He was diagnosed to have 


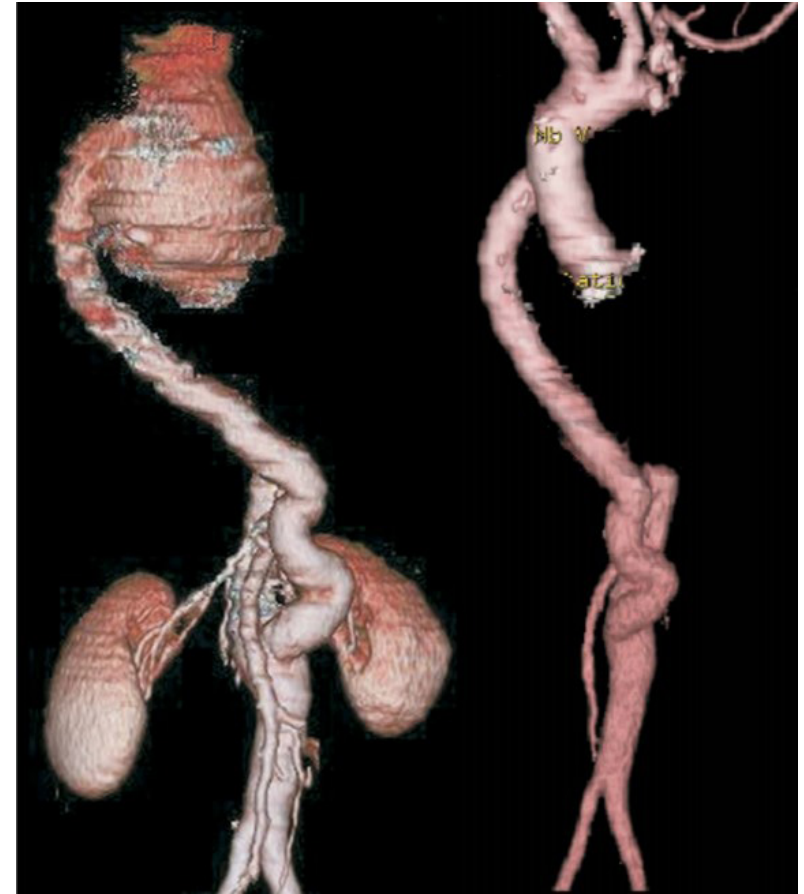

Figure 5 CT Aortogram of case \#4. Preoperative image showing the patent extra-anatomical prosthetic graft from the ascending aorta to the abdominal aorta. Note the dilated ascending aorta. Postoperative image showing Bentall's procedure with the reimplantation of the extraanatomic prosthetic graft to the neo ascending aorta.

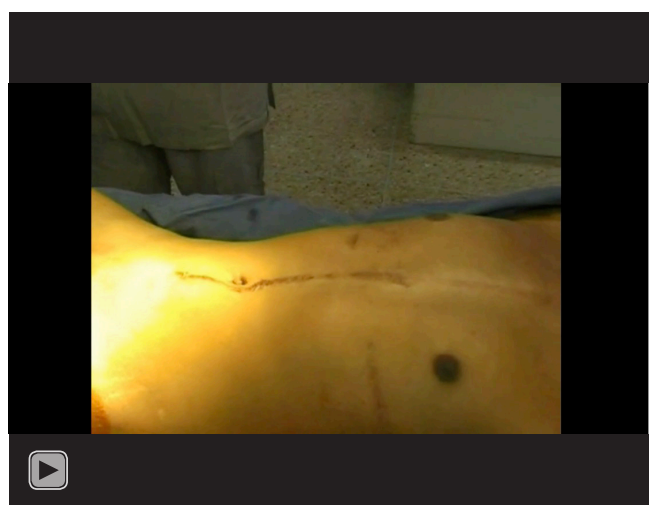

Video 4 Operative video of case \#4.
CoA with ascending aortic aneurysm. Echocardiogram showed severe aortic stenosis and severe left ventricular dysfunction (ejection fraction $30 \%$ ). He underwent stenting of CoA and was then offered Bentall's procedure with hemi arch replacement in the same admission (Figure 6).

\section{Regression of collaterals}

There is no literature to suggest the time for regression of the collaterals. In our personal experience, we have seen the collaterals regressing as early as sixth postoperative period (Figure 7).

\section{Limitations}

With no definitely guidelines, at present the treatment plan has to be tailored to individual patients. These results of these surgical procedures are from large case series or retrospective analysis. In future, there is a need for randomised control study to identify the definitive treatment strategy for these patients.

\section{Summary}

* The difference in management between the adult and paediatric patient has been discussed.

* The different management strategies with surgery, endovascular and hybrid approach has been discussed.

* Surgery still has an important role in the management of adult CoA.

* Most of the isolated CoA can be performed through left lateral thoracotomy without the need of CPB.

* The associated cardiac pathologies need to be considered to decide on the type of surgery to be provided. Currently, a single-stage operation with hybrid procedures might be a good option for most cases.

* Soon we will be encounter patients who has been operated at the childhood, presenting with either recurrence of CoA or associated cardiac problems. 

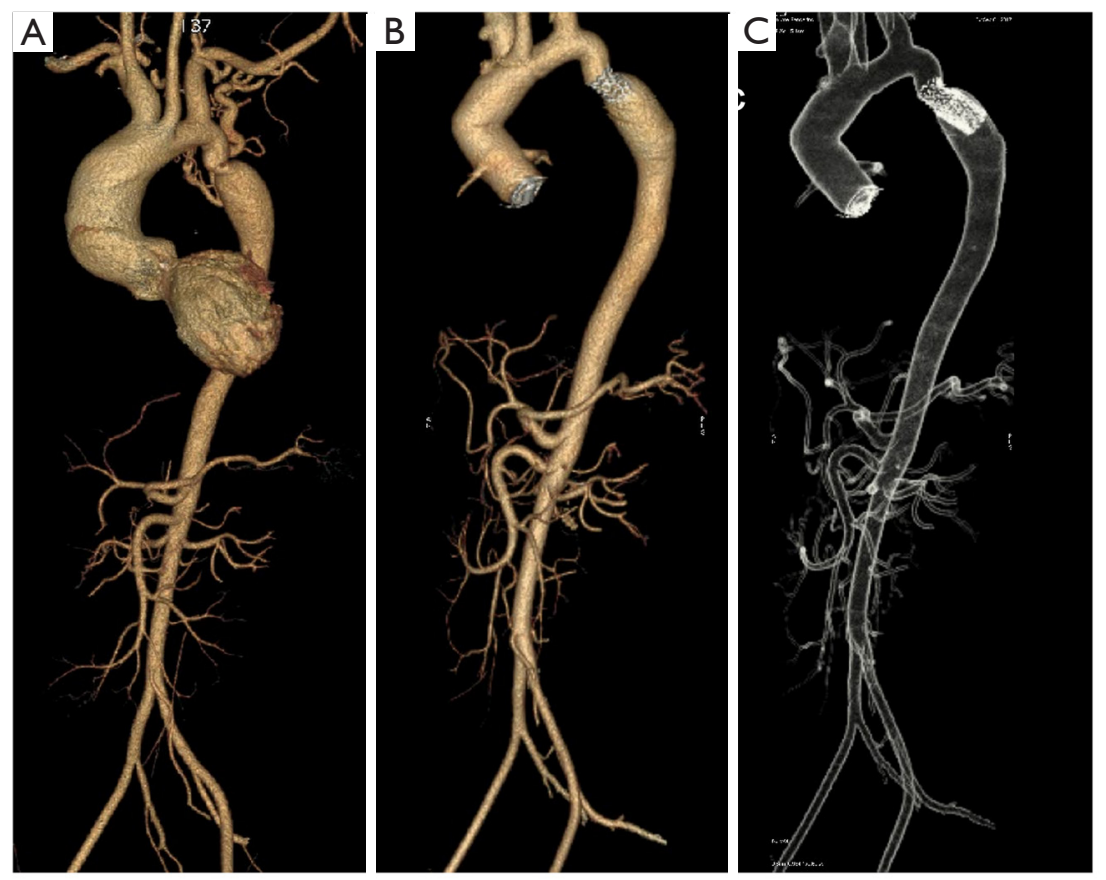

Figure 6 A 37-year-old male with CoA and ascending aortic aneurysm (case \#5). Preoperative CT aortogram showing CoA with ascending aortic aneurysm (A). The patient underwent hybrid procedure—stenting of CoA and Bentall's procedure with hemi arch replacement (B,C).
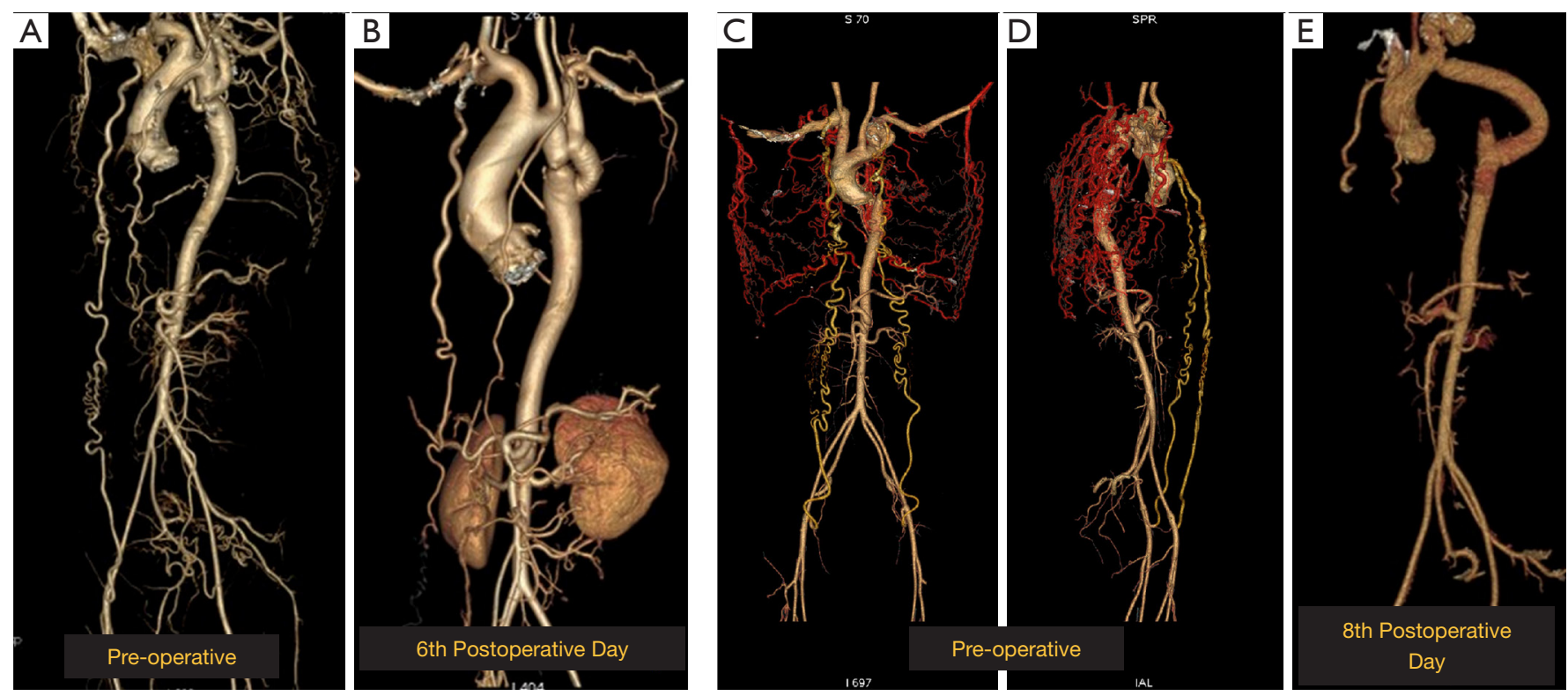

Figure 7 Regression of collateral. (A) Extensive collaterals in a 28-year-old female patient with CoA. (B) CT aortogram on the $6^{\text {th }}$ postoperative day showing marked regression of collaterals (C,D). Marked collateral in a 34-year-old female with long segment CoA. (E) Regression of the collaterals on the $8^{\text {th }}$ postoperative day. 


\section{Acknowledgments}

Funding: None.

\section{Footnote}

Provenance and Peer Review: This article was commissioned by the Guest Editors (Roberto Di Bartolomeo, Davide Pacini, Mohamad Bashir) for the series "the 10 th Postgraduate Course on 'Surgery of the Thoracic Aorta' in Bologna" published in fournal of Visualized Surgery. This article has undergone external peer review.

Reporting Checklist: The authors have completed the Narrative Review reporting checklist. Available at https:// jovs.amegroups.com/article/view/10.21037/jovs-19-196/rc

Conflicts of Interest: Both authors have completed the ICMJE uniform disclosure form (available at https://jovs. amegroups.com/article/view/10.21037/jovs-19-196/coif). The series "the 10th Postgraduate Course on 'Surgery of the Thoracic Aorta' in Bologna" was commissioned by the editorial office without any funding or sponsorship. Both authors have no other conflicts of interest to declare.

Ethical Statement: The authors are accountable for all aspects of the work in ensuring that questions related to the accuracy or integrity of any part of the work are appropriately investigated and resolved. All procedures performed in this study were in accordance with the Helsinki Declaration (as revised in 2013). The manuscript is waived from patient informed consent according to the ethics committee or institutional review board.

Open Access Statement: This is an Open Access article distributed in accordance with the Creative Commons Attribution-NonCommercial-NoDerivs 4.0 International License (CC BY-NC-ND 4.0), which permits the noncommercial replication and distribution of the article with the strict proviso that no changes or edits are made and the original work is properly cited (including links to both the formal publication through the relevant DOI and the license). See: https://creativecommons.org/licenses/by-nc-nd/4.0/.

\section{References}

1. Baumgartner H, Bonhoeffer P, De Groot NM, et al. ESC Guidelines for the management of grown-up congenital heart disease (new version 2010). Eur Heart J
2010;31:2915-57.

2. Novotný J, Peregrin JH. Endovascular management of coarctation of the aorta in adult patients. Cor et Vasa 2015;57:e181-e186.

3. Mahadevan V, Mullen MJ. Endovascular management of aortic coarctation. Int J Cardiol 2004;97 Suppl 1:75-8.

4. Turner DR, Gaines PA. Endovascular management of coarctation of the aorta. Semin Intervent Radiol 2007;24:153-66.

5. Crafoord C, Nylin G. Congenital coarctation of the aorta and its surgical treatment. J Thorac Surg 1945;14:347-61.

6. Beekman RH, Rocchini AP, Behrendt DM, et al. Longterm outcome after repair of coarctation in infancy: subclavian angioplasty does not reduce the need for reoperation. J Am Coll Cardiol 1986;8:1406-11.

7. Walhout RJ, Lekkerkerker JC, Oron GH, et al. Comparison of polytetrafluoroethylene patch aortoplasty and end-to-end anastomosis for coarctation of the aorta. J Thorac Cardiovasc Surg 2003;126:521-8.

8. Ramnarine I. Role of surgery in the management of the adult patient with coarctation of the aorta. Postgrad Med J 2005;81:243-7.

9. Gudbjartsson T, Mathur M, Mihaljevic T, et al. Hypothermic circulatory arrest for the surgical treatment of complicated adult coarctation of the aorta. J Am Coll Cardiol 2003;41:849-51.

10. Yilmaz M, Polat B, Saba D. Single-stage repair of adult aortic coarctation and concomitant cardiovascular pathologies: a new alternative surgical approach. J Cardiothorac Surg 2006;1:18.

11. Ma L, Gu Q, Ni B, et al. Simultaneously surgical management of adult complex coarctation of aorta concomitant with intracardiac abnormality. J Thorac Dis 2018;10:5842-9.

12. Nair KR, Vasu H, Jacob A, et al. Aortic root replacement in a patient with previous multiple surgeries for coarctation of aorta. Ann Thorac Surg. 2009;87:930-3.

13. Li Q, Lin K, Gan CP, et al. One-Stage Hybrid Procedure to Treat Aortic Coarctation Complicated by Intracardiac Anomalies in Two Adults. Ann Thorac Surg 2015;100:2364-7.

doi: 10.21037/jovs-19-196

Cite this article as: Velayudhan BV, Idhrees AM. Coarctation of aorta in adults: a narrative review of surgical and endovascular management. J Vis Surg 2021;7:17. 